\section{Clinital Mtotes:}

\section{MEDICAL, SURGICAL, OBSTETRICAL, AND THERAPEUTICAL.}

A CASE OF MITRAL STENOSIS; DEATH FROM EMBOLISM OF SIX MAIN ARTERIES.

By Richard S. Roper, M.R.O.S. ENG., L.R.C.P. LOND.

A MAN, aged 27 years, was admitted to the St. Marylebone Infirmary on Oct. 26th, 1905, suffering from cardiac disease and bronchitis. He had had rheumatic fever twice. On admission he complained of cough but otherwise seemed in fair healtb. On examination there were a few râles and rhonchi scattered over both lungs. The cardiac area of dulness was increased and on auscultation well-marked systolic and mid-diastolic bruits were heard at the apex. No other bruits were heard. The pulse was regular and of good volume. The liver was not enlarged, neither was there any ascites, œdema, or other sign of failing compensation. The patient was kept in bed for a month and as at the end of that time all physical signs in the lungs had subsided he was allowed up and by Dec. 7th was up all day.

On Dec. 7th, at 4.45 P.M., while in the day-room the patient suddenly became very ill and was at once removed to bed. When examined he was blue, pulseless, cold, and clammy, and was struggling vigorously, and at the same time complained of great pain in his legs. The heart was beating regularly and at normal rate but no bruits could be heard. At 7 P.M. the general appearance of the matient was much the same and the condition of collapse was very little improved. He still complained of great pain in the knees and abdomen. Neither tibial pulse could be felt nor was there any pulse at the left wrist. The left femoral artery could be felt pulsating just below Poupart's ligament. Both lower limbs and the left arm were paralysed. There was anæsthesia of the legs as far up as Poupart's ligament. The abdomen was slightly distended. At no time was he unconscious and his mental condition was quite clear. A sixth of a grain of morphine acetate was given and at 10 P.M. he had somewhat recovered and had less pain. At this time his face was a natural colour, the collapse had passed off, and he was warm. He was still unable to move mis left arm but motor power and sensation had returned to the lower limbs. The right radial was the only artery felt pulsating in the limbs. The abdomen now was very diswended and a copious blood stained motion was passed. Several ounces of blood were passed per rectum until death, which took place at 4 A.M. on Dec. 8th.

A post-mortem examination was made seven hours after death. There was hypertrophy of the left auricle and ventricle with marked stenosis of the mitral orifice. The latter just admitted the tip of one finger. Recent vegetations were present on the inner wall of the left auricle of the size of a pea. No ante-mortem clot was to be seen. The small intestines were distended and anæmic. Embolism of the following arteries was found: both common femorals with ante-mortem clot extending as far as the popliteal artery; the right internal iliac at its bifurcation; the right renal at its division; the superior mesenteric just below the middle colic branch; and the left brachial at the origin of the superior profunda. No other pathological condition was found in any organ.

I am indebted to Mr. J. R. Lunn, medical superintendent, for permission to publish this case.

Notting Hill, w.

\section{A CASE OF LEUK WITH ARSENIC.}

By Frank Lindsay Dickson, M.B., Сh.B.Glasg.

THE patient in the following case was a man, aged 24 years, who came to me on May 30th complaining of pain in the back, slight headache, and general debility. His temperature was $99.6^{\circ} \mathrm{F}$. and I gave him a saline mixture 'with orders to rest'for a few days. He'returned three days later and stated that the pain in the back was better but that he felt very weak. His temperature was normal and I treated the case as debility following influenza, prescribing compound syrup of the hypophosphites and codliver oil. At the same time I noticed a slight swelling of one of the deep cervical glands. This was hard, freely moveable, and quite painless. The patient then took to his bed, there being great prostration. The glandular enlargement ircreased until the swelling was of about the size of a hen's egg. His temperature remained normal and there was no improvement in his general condition.

On the evening of June 6 th I found that the inguinal, right axillary, and post-cervical glands were slightly enlarged; the splenic area of dulness was slightly increased and pain was induced on pressure over that organ. I was inclined to diagnose the case as one of pseudo-leukæmia, true leukæmia to be left for consideration after examination of the blood, for which purpose I sent him to the Queen's Hospital, Birmingham. The patient was seen by Dr. J. G. Exanuel, who afterwards told me that he was inclined to regard the case as one of mild enteric fever. A blood film was, however, taken and on the next morning I received from Dr. Emanuel a letter from which the following is an extract: "There is a great excess of leucocytes and lymphocytes, the latter predominating. I regard it as being one of those rare cases of acute or subacute lymphatic leukrmia. I expect it will terminate fatally in a few weeks." I examined the blood myself on the following day and found that the white cells were almost as numerous as the red ones. I then commenced to administer liquor arsenicalis, giving five minims three times a day, and the result seemed almost miraculous. After three days the patient "felt much better in himself," the glandular swellings were noticeably less, and I found that there was marked improvement in the condition of the blood. The dose of liquor arsenicalis was increased rapidly unti 15 minims were being taken thrice daily, the improvement continuing and no toxic symptoms being produced by the drug. The patient had one attack of epistaxis which weakened him a little; he had, however, been subject to these attacks from childhood. About a fortnight later the glands were practically normal and the blood was, in my opinion, in a like condition. Dr. Emanuel came to see him after I had written my opinion on the subject and took half a dozen films of the blood. His next letter said that "the blood is practically normal."

The dose of arsenic was gradually diminished and on July 6th the patient went to the seaside for a fortnight, taking with him sufficient medicine to last him till his return. I gave him iron in addition to the arsenic as the red blood corpuscles needed a little recruiting. On his return be told me that he felt as well as ever he had done in his life. Two days later he returned to his work as a carpenter and he has remained perfectly well ever since. The only predisposing cause was that some time before the commencement of the illness he had been working about some waterclosets of which the drains were obstructed and the odours not ambrosial.

Hay Mills, Birmingham.

\section{A CASE OF RUPTURE OF THE GRAVID FALLOPIAN TUBE.}

BY N. J. F. VAZIEDAR.

THE patient was an ayah, aged 25 years, who was admitted into the Sir Jamsetjee Jeejeebhoy Hospital in Bombay on Dec. 9th, 1905, for acute intestinal obstruction. The history of her illness was that on Dec. 6th, whilst micturating, she was suddenly seized with an acute pain in the abdomen after which she vomited and fainted. The pain and vomiting increased and on the 8 th the vomited matter became fæcal. There was absolute con stipation in addition to which no flatus had been passed since the 6th. On admission she was in a collapsed con. dition. Her temperature was $97^{\circ} \mathrm{F}$., her pulse was 146 per minute and very weak, and her respirations were 48 per minute; the abdomen was much distended all over, tense and hard on palpation, and tympanitic on percussion. There was almost continuous freal vomiting. The case being diagnosed as one of acute intestinal obstruction, probably due to a volvalus, a median laparotomy was immediately 
performed by Lieutenant-Colonel W. H. Quicke, I.M.S., the senior surgeon of the hospital. The abdominal cavity was then found to be full of dark blood and blood clots, and further examination revealed a rupture of the right Fallopian tube at its isthmus. The tube was tightly ligatured at its uterine junction, the broad ligament was also ligatured $e n$ masse, the whole tabe with the ovary was removed, and the abdomen was sutured after being flushed with hot normal saline solution. An intravenous injection of 24 ounces of normal saline solntion had to be given. The ruptured foetal membranes with slender chorionic villi were found among the blood clots. Tke patient was in a very precarious state and had to be supported on stimulating injections for three or four days. She then gradually improved and was discharged recovered on Jan. 29th, 1906.

A very remarkable fact in the case was that the patient on admission showed all the signs and symptoms of acute intestinal obstruction, including extremely severe fæcal vomiting, and the history of her illness as given at the hospital did not contain any clue to its real nature. Owing to the enormous distension of the whole of the abdomen no localised swelling could be distinguished. There was even a history of the patient having a normal menstrual period a week before the illness.

This is the third case of rupture of the gravid Fallopian tube at the end of the fifth week which has been admitted into this hospital during the last two years. All these patients had symptoms and signs pointing most distinctly to intestinal obstruction; and they all had constipation of three or four days' duration, fæcal vomiting, and great distension of the abdomen.

I have to thank Lieutenant-Colonel Quicke for permitting me to report the case.

The Sir Jamsetjee Jeejeebhoy Hospital, Bombay.

\section{9 解irtor}

or

\section{HOSPITAL PRACTICE, BRITISH AND FOREIGN.}

F aila autem est alia pro certo noscendi via, nisi quamplurimas et murborum et dissectionum historias, tum aliorum tum proprias Morb., lib. iv., Procmium.

\section{KIDDERMINSTER INFIRMARY.}

WO UNIQUE CONGENITAL DEFORMITIES IN THE ABDOMEN OF THE SAME PATIENT.

(Under the care of Mr. J. LIONEL STRETTON)

A Boy, aged five years, was admitted to the Kidderminster Infirmary on July 14th last. He suffered from pain in the abdomen. He vomited some curdled milk soon after admission but after this he retained the milk given to him. His mother stated that he had suffered from pains in the abdomen and occasional vomiting since birth. His bowels were always very constipated. On examination it was noted that he was very thin and emaciated. The abdomen was retracied. On inspection a lump swelled up and became lisible in the epigastric region about an inch above, and to the right of, the umbilicus. Vermicular action of the intestine was seen from the right iliac region up to this lamp. On palpation the lump could be easily felt; it was a out two inches in diameter and of an ovoid shape and could be grasped between the thumb and fingers witbout causinx pain. In the left iliac region some small indurated $m$ tsies were felt resembling enlarged glands. Per rectum the finger passed in easily. At a point about three inches from the anus a sharp, sickle-like band was felt, apparently attached to the anterior wall of the pelvis and impinging on the rectum, and though not interfering with its calibre it would probably do so if the bowel was loarled. Examination of the chest discovered nothing abnormal. The pulse and temperature were normal. An enema was administered and brought away a quantity of small, scybalous masses. Examination of the abdomen after this failed to discover the $\mathrm{small}$ indurated masses in the left iliac region that had been mistaken for glands. The patient was given small quantities of milk which were retained. The most probable diagnosis appeared to be tuberculous peritonitis with partial occlusion of the transverse colon.

On July 17th, under ether, an incision about two inches long was made in the left linea semilunaris from the level of the umbilicus downwards. No evidence of tubercle was discovered. The band in the pelvis appeared to be a fold of peritoneum running along the whole of the anterior surface of the pelvis and projecting backwards about one inch. The lump in the epigastric region was felt to involve the pylorus. A second incision was made runnirg upwards from the umbilicus in the middle line about two inches in length. The lump was then lifted out of the abdomen. It was found to consist of an enlargement of the cardiac end of the stomach close to the pylorus. The transverse colon was closely adherent, which caused a loop and would interfere with the free passage of its contents. The lump appeared to be connected with the walls of the stomach; it was ovoid in shape about two inches in diameter, and tense and elastic. As the nature of it was uncertain it was decided to explore it. After separating the colon clamps were applied on either side and a longitudinal incision was made over it on its anterior aspect. About three drachms of clear serous fluid immediately escaped and the finger entered a cyst which had no communication with the stomach or intestine. The cyst wall was found to be attached to the muscular wall of the stomach. It was situated between this and the mucous membrane which it had pushed downwards. It was very intimately attached posteriorly, above, and in front. How much it had occluded the pylorus it was impossible to say as the fluid had escaped before the nature of the enlargement was discovered. An endeavour was made to dissect off the wall but it was so adherent that it was impossible to avoid penetrating the walls of the stomach and it was necessary to excise this portion. The ends were united with silk sutures and the abdominal wounds were closed. The patient suffered from considerable shock, after which he improved for a day or two, but died early on the 21st from exhaustion.

The specimen was sent to the Clinical Research Associa. tion and it reports as follows: "From the naked.eye appearance and microscopic structure of this cyst wall we can form no definite opinion as to its origin. It is composed of closely felted fibrous tissue which is smooth on one surface but entirely devoid of any epithelial covering. Externally there is loose cellular tissue and interlacing bundles of unstriped muscle. From the youtn of the patient it is probable that the cyst is of congenital origin."

Necropsy.-Post-mortem examination showed some recent peritonitis. The anastomosis was quite secure. The crescentic band felt on the anterior wall of the pelvis consisted of a peritoneal fold projecting backwards from the posterior surface of the bladder and ending in $a$ horn running up on each side wall of the pelvis just posterior to the position of the ureters. It stood out one and a quarter inches at the centre, gradually diminishing as it approached the sides. There was a second less marked peritoneal fold along the upper surface of the blarder.

Remarks by Mr. STRETTON. - I can find no record of either of these conditions. Of the cyst I can offer no further expla nation than that given by the Clinical Research Association A congenital cyst in this situation must be exceedingly rare, if indeed, it has ever before been found. The fold of peritoneum was no doubt an unusual development of the sacro-genital fold so well depicted in Professor D. J. Cunningham's "Text book of Anatomy" (Figs. 822 and 833). Although always present. I have never before been able to feel it per rectum and so far have not heard of it being felt. In this opinion I am strengthened by a letter from Dr. D. Waterston of the University of Elinburgh who, in answer to a question from my house surgeon, Mr. W. A Wilson-Smith, says: "I have of ten wondered if it could not be felt per rectum but yours is the first instance to my knowledge." Both the conditions, therefore, appear to be worth reporting and it is a curious fact that they should have been found in the same abdomen.

Donations and Bequests. - The late Mrs. H Finnie has bequeathed $£ 2000$ to the Clevedon (Somerset) Convalescent Home and her executors have allotted the sum of $£ 1000$ to the Royal Sea Batbing Hospital, Margate, for the endowment of the "Hannah Finnie memorial bed." 